\title{
Lipase-catalyzed modification of butterfat via acidolysis with oleic acid ${ }^{1}$
}

\author{
Victor M. Balcão, F. Xavier Malcata * \\ Escola Superior de Biotecnologia, Universidade Católica Portuguesa, Rua Dr. António Bernardino de Almeida, 4200 Porto, Portugal
}

\begin{abstract}
During the last decade increased interest in reactions catalyzed by lipases from various microbial sources has prompted attempts to rationally design lipases and lipase-catalyzed processes aiming at modification of functional properties of oils and fats. The present communication reports experimental work on the chemical modification of anhydrous butterfat via interesterification reactions with oleic acid catalyzed by a commercial lipase immobilized by plain physical adsorption on a bundle of hydrophobic hollow fibers. The main gual of this research effort was to engineer butterfat so as to increase its level of unsaturated fatty acid residues (viz. oleic acid) and concomitantly decrease its level of medium-to-long chain saturated fatty acid residues (viz. myristic and palmitic acids). All reactions were carried out at $40^{\circ} \mathrm{C}$ in the absence of any solvent but under controlled water activity, and their extent was monitored via chromatographic assays for free fatty acids. Although a certain degree of net hydrolysis of butterfat was observed, the enzymatic process studied was technically feasible and able to reach the predefined goals.
\end{abstract}

Keywords: Butterfat; Fatty acid; Lipase: Mucor javanicus; Hollow fiber reactor: Interesterification; Immobilization.

\section{Introduction}

Oils and fats from natural sources are complex mixtures of triglycerides containing different stereochemical combinations of fatty acid residues; the concentrations of all such types of triglycerides determine most physical and chemical properties of said oils and fats. Engineering of oils and fats via changes in the combinations of fatty acid residues esterified to the glycerol backbone of triglycerides and/or changes in the relative concentrations thereof have allowed

\footnotetext{
* Corresponding author.

${ }^{1}$ Part of the information conveyed in this paper was presented at the International Workshop on Microbial Lipases in the Biocatalysis, April 11-13, 1996, Rome, Italy
}

production of oils and fats with tailor-made functional properties which include (but are not limited to) a narrower melting range [1,2] and a higher stability against oxidation [3]. Most technologies for modification of oils and fats which have met with commercial success make use of mixing, hydrogenation, and fractionation. However, with the exception of mixing, most of these processes are rather aggressive to edible oils and fats due to use of chemical catalysts at relatively high temperatures or solvents at relatively high concentrations, and hence usually require downstream refining. Such drawbacks have promoted an increased interest towards lipase-catalyzed reactions in solvent-free systems because these enzymes possess good activity and selectivity towards their natural sub- 
strates at mild room processing conditions and in their action mimic environment-friendly (bio)chemical routes.

Three major groups are found in the triglyceride population of milkfat [4]: (i) one such group is composed of molecules containing 4854 carbon atoms and is rich in long-chain saturated fatty acids and oleic acid; (ii) another group is composed of molecules containing 3646 carbon atoms and possesses a structure similar to the first group except for the sn-3 position where short-chain fatty acids tend to be esterified; (iii) the third group is composed of molecules containing 26-34 carbon atoms especially accounted for by medium- and short-chain fatty acids. Butterfat contains mainly mediumand long-chain saturated fatty acids [1] and their stereochemical distribution gives rise to relatively high average melting points. Because butterfat contains appreciable quantities (ca. 28\% $\mathrm{w} / \mathrm{w}$ ) of oleic acid residues [5], which are distributed between the sn-1, sn-2, and sn-3 positions at ca. 21,14 , and $15 \%(\mathrm{~mol} / \mathrm{mol})$, respectively [6], and since this monounsaturated fatty acid possesses cholesterol-alleviating effects, a modified butterfat with better nutraceutical properties could be obtained via exchange of the hypercholesterolemic lauric, myristic, and palmitic acid residues in the glycerides of butterfat by externally supplied oleic acid residues.

In this work the interesterification of anhydrous butterfat was brought about by a lipase immobilized by adsorption onto a bundle of hydrophobic hollow fibers. Our study aimed primarily at producing butterfat with a higher content of oleic acid residues via processing at a relatively mild temperature and using an immobilization protocol prone to regeneration of deactivated lipase.

Although acidolysis may be used to lower the saturated fatty acid content of butterfat, it can also, depcnding on the reaction conditions and the selectivity characteristics of the lipase used, generate glycerides with a fatty acid profile in terms of short-chain fatty acids such that the base buttery flavor will no longer be present; special care was thus exercised in this research effort in order to increase the oleic acid content of butterfat without effecting (major) alterations in the inventory of short-chain fatty acid residues. Furthermore, interesterification was carried out in a solvent-free system as done by a number of authors [7-9] because, although hydrocarbon solvents facilitate reaction by lowering the viscosity of the reaction medium, their use requires the reaction product(s) to be bleached, deodorized and refined for nutritional safety and consumer appeal [7].

\section{Experimental}

\subsection{Materials}

\subsubsection{Enzyme}

The lipase used was a commercial crude powder $\left(\mathrm{M}^{\mathrm{TM}}\right)$ obtained from Mucor javanicus and kindly supplied by Amano Pharmaceutical (Nagoya, Japan).

\subsubsection{Apparatus}

A laboratory module of microporous polypropylene hollow fibers (Liqui-Cell ${ }^{\mathrm{TM}}$ $\mathrm{X} 10 / 240$ ) was purchased from Hoechst Celanese (Charlotte, NC). This laboratory unit is $30 \mathrm{~cm}$ long and $2.5 \mathrm{~cm}$ in diameter, and contains ca. 1000 fibers that are ca. $23 \mathrm{~cm}$ long. These food grade fibers have a nominal internal diameter of $240 \mu \mathrm{m}$, a nominal porosity of ca. 0.60 , and a nominal pore size of ca. $0.2 \mu \mathrm{m}$; the resulting effective membrane area is thus ca. $0.23 \mathrm{~m}^{2}$. The water bath was equipped with a mechanical agitator and a digital temperature controller (Julabo Labortechnik GmbH, Seelbach, Germany). Recirculation of fluids was achieved with high-precision metering pumps (ISMATEC MC-Z, Zürich, Switzerland).

\subsubsection{Chemicals}

Citric acid monohydrate, o-phosphoric acid $(85 \%, \mathrm{v} / \mathrm{v})$, Coomassie brilliant blue G-250, ethanol for spectroscopy (UVASOL ${ }^{\mathrm{TM}}$ ), diethyl 
ether, isooctane, potassium carbonate, albumin fraction V (from bovine blood serum), sodium hydroxide, and anhydrous sodium sulfate were obtained from Merck (Darmstadt, Germany); 18-crown-6-ether was purchased from Merck (München, Germany); butylated hydroxyanisole, $p$-bromophcnacylbromide, and potassium phosphate were from Sigma (St. Louis, MO); chloroform, formic acid, acetonitrile $\left(190^{\mathrm{TM}}\right)$, and methanol $\left(205^{\mathrm{TM}}\right)$ were from ROMIL Chemicals (Leicester, UK). All free fatty acid standards ( $>99.9 \%$ pure) were obtained from Sigma. Fermentation ethanol $(96 \%$ $\mathrm{v} / \mathrm{v}$ ) was obtained from AGA (Portugal). Dry nitrogen $\left(\mathrm{C}-55^{\mathrm{MM}}\right)\left(<1 \mathrm{ppm} \mathrm{H}_{2} \mathrm{O}\right.$ and $<1 \mathrm{vpm}$ $\mathrm{O}_{2}$ ) and liquid nitrogen were purchased from Carburos Metalicos (Barcelone, Spain). All chemicals purchased were reagent-grade or better and were used without further purification. Tap water was subject to successive steps of reverse osmosis, adsorption, deionization, microfiltration and photo-oxidation in a Milli-Q Plus 185 water purification system (Molsheim, France) to a final conductivity of $18.2 \mathrm{M} \Omega$ $\mathrm{cm}^{-1}$.

\subsubsection{Substrates}

Salt-free, pasteurized butter was purchased from PROLEITE (Oliveira de Azeméis, Portugal) and kept in sealed plastic bags of ca. $1.5 \mathrm{~kg}$ at $-30^{\circ} \mathrm{C}$ until experimental use. Oleic acid (95\% pure) was obtained from Sigma.

\subsubsection{Analytical equipment}

Nylon membrane filters (NALGENE ${ }^{\mathrm{TM}}, 0.45$ $\mu \mathrm{m}$ ) were purchased from Nalge (New York, NY). Disposable cuvettes for the spectrophotometric readings were purchased from Kartell (Italy). The HPLC equipment (Beckman Instruments, San Ramon, CA) utilized consists of an autosampler with temperature control for the column (model 502), a C-18 reversed-phase column $(25 \mathrm{~cm} \times 4.6 \mathrm{~mm} \times 5 \mu \mathrm{m})$ coupled with a pre-column cartridge $(4.5 \mathrm{~cm} \times 4.6 \mathrm{~mm} \times 5$ $\mu \mathrm{m})$, a solvent delivery system with two pumps
(Progranmable Solvent Module 126), a programmable multiwavelength spectrophotometer (Diode Array Detector Module 168), and a software package for system control and data acquisition (GOLD v6.01). Karl-Fischer titration was carried out with a 684 KF Coulometer (Metrohm, Switzerland). The differential scanning calorimeter (Shimadzu, Kyoto, Japan) consisted of a detector (DSC-50) coupled with a Thermal Analyzer (TA-501).

\subsection{Methods}

\subsubsection{Preparation of anhydrous butterfat}

Butter was pretreated by the procedure of Kalo et al. [7] with slight modifications: water was removed from butter in a separating funnel at $60^{\circ} \mathrm{C}$, and fat was then filtered out using normal filter paper and dried in a vacuum of $\mathrm{ca}$. $800 \mathrm{mbar}$ for $1 \mathrm{~h}$ in a boiling water bath. After drying via passage through a silica column, nitrogen was bubbled in the melted butterfat for ca. $1 \mathrm{~h}$ (to help in removing residual oxygen and water), and the dried fat thus obtained was stored in sealed plastic bags at $-30^{\circ} \mathrm{C}$ until experimental use.

\subsubsection{Preparation of Mcllvaine buffer}

The Mcllvaine buffer was prepared according to the procedure described by Dawson et al. [10]: $3.71 \mathrm{~g}$ of citric acid dissolved in $176.5 \mathrm{ml}$ of deionized water was added to a solution of $37.59 \mathrm{~g}$ of potassium monohydrogenophosphate in $823.5 \mathrm{ml}$ of deionized water, and the $\mathrm{pH}$ of the resulting buffer was adjusted to 7.0 using sodium hydroxide.

\subsubsection{Preparation of Coomassie reagent}

The working solution of Coomassie Brilliant Blue G-250 was prepared according to the procedure described by Robyt and White [11]: 100 $\mathrm{mg}$ of Coomassie Brilliant Blue G-250 was dissolved in $50 \mathrm{ml}$ of ethanol, added to $100 \mathrm{ml}$ of $85 \% o$-phosphoric acid, and the resulting solution was diluted to 11 with deionized water. 


\subsubsection{Immobilization of lipase}

Due to the hydrophobic character of the hollow fibers, the reactor was prewet via rinsing with a series of liquids prior to every enzyme immobilization: absolute ethanol for ca. $15 \mathrm{~min}$ (to completely fill the pores in the fibers and assist in removal of air bubbles), ultrapure water for ca. $15 \mathrm{~min}$ (to strip ethanol away, until it could not be detected by smell in the effluent stream), and Mcllvaine buffer for ca. $10 \mathrm{~min}$ (to establish the convenient $\mathrm{pH}$ ). For cach experiment, $250 \mathrm{ml}$ of lipase solution $(1.692 \mathrm{~g}$ of

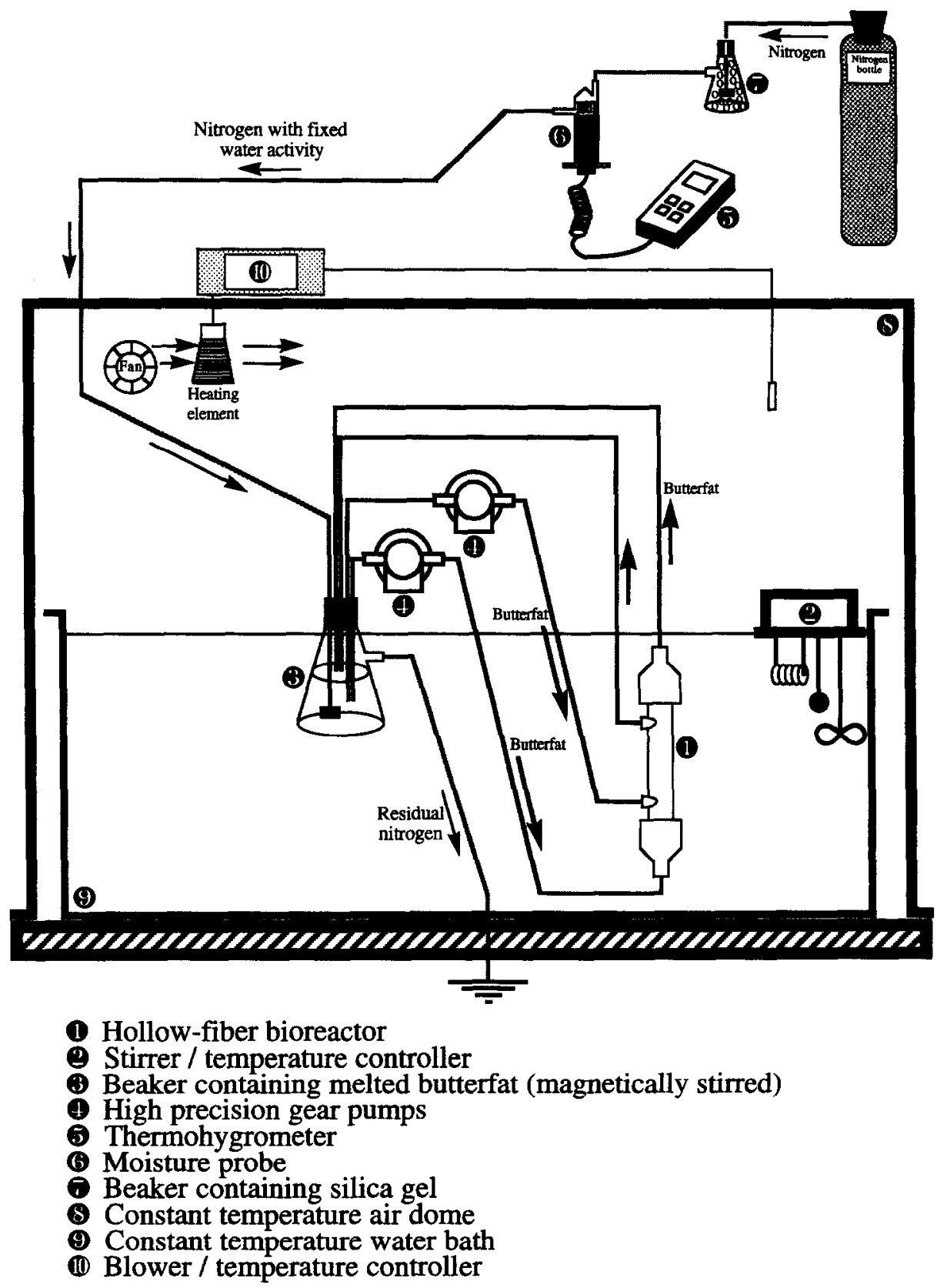

Fig. 1. Experimental setup used for the lipase-catalyzed interesterification of butterfat. 
crude lipase powder per liter of McIlvaine buffer) [12] was poured into a stirred beaker and recirculated for ca. $10 \mathrm{~h}$ through both the lumen and the shell sides of the fibers in the module at a flow rate of ca. $112 \mathrm{ml} / \mathrm{h}$ using a high precision metering pump. After each interesterification reaction experiment, and before the next experiment, the hollow fiber module was rinsed with diethyl ether and ethanol $(50 \%, v / v)$ for ca. $20 \mathrm{~min}$ (to remove butterfat and adsorbed protein from the hollow fibers), and ultrapure water for ca. $15 \mathrm{~min}$ (in order to strip diethyl ether/ethanol away from the membrane pores); from then on, the procedure was as described previously.

\subsubsection{Protein assays}

The amount of protein adsorbed on the fibers of the reactor was obtained by difference between the protein content of the supernatant solutions before and after the immobilization procedure. The assays for protein followed the Coomassie Brilliant Blue G-250 method [12]; this method (also known as the Bradford method) basically consisted in adding $0.5 \mathrm{ml}$ aliquots of the solution of crude lipase in Mcllvaine buffer to $4.5 \mathrm{ml}$ of Coomassie reagent, followed by measuring absorbance after $5 \mathrm{~min}$ at $595 \mathrm{~nm}$ using disposable cuvettes. Plain McIlvaine buffer was used as the blank. Protein content was determined from such absorbance readings by means of a calibration curve previously prepared with aqueous solutions of bovine serum albumin with concentrations ranging from 0 to $500 \mu \mathrm{g} / \mathrm{ml}$.

\subsubsection{Interesterification reactions}

All butterfat modification reactions were carried out at $40^{\circ} \mathrm{C}$ using the experimental setup depicted in Fig. 1. This setup encompasses a hollow-fiber bioreactor unit immersed in a constant temperature bath equipped with a mechanical agitator and a digital temperature controller. Upon completion of the lipase immobilization procedure, and immediately before start-up of each experiment, the following sequence of pro- cedures was followed: the reactor was placed upside down and the reactant mixture (melted dry butterfat added with $7 \%(\mathrm{v} / \mathrm{v})$ oleic acid) was pumped through the reactor (so as to completcly replace the aqueous buffer in the lumenand shell-sides of the fibers), the reactor was reverted to its regular operating position (inlet streams at the bottom), and the reactant mixture was circulated for an extra $2 \mathrm{~min}$ (before starting the stopwatch). The whole system was kept under a perspex dome with the air temperature controlled at $40 \pm 3^{\circ} \mathrm{C}$ (in order to prevent solidification of the mixture of butterfat with oleic acid in the tubing). Recirculation of the reacting melted mixture through the reactor was accomplished via action of two high-precision metering pumps. Volumes of reactant mixture typically ranging from $350 \mathrm{ml}$ to $375 \mathrm{ml}$ were recirculated for ca. $150 \mathrm{~h}$ through the lumen side and shell side of the hollow fibers at flow rates of ca. $35 \mathrm{ml} / \mathrm{h}$ and ca. $31 \mathrm{ml} / \mathrm{h}$, respectively, in order to obtain similar space times in both sides. Throughout each experiment, dried nitrogen was bubbled in the recirculating fat mixture in the beaker (to assist in water and oxygen removal and thus prevent hydrolysis and oxidation of butterfat). Aliquots were withdrawn at regular time intervals from the beaker containing the recirculating fat mixture and assayed for free fatty acids and thermal behavior.

\subsubsection{Free fatty acid assays}

Free fatty acids in plain butterfat and in the reactant mixture were analyzed by HPLC according to the procedures by Garcia et al. [13] and Malcata [14], with slight modifications.

For calibration, stock solutions of 12 different free fatty acid standards, viz. C4:0 (butyric acid), C6:0 (caproic acid), C8:0 (caprylic acid), C10:0 (capric acid), C12:0 (lauric acid), C14:0 (myristic acid), C16:0 (palmitic acid), C18:0 (stearic acid), C18:1 (oleic acid), C18:2 $\omega 6$ (linoleic acid), C18:3 $\omega 6$ ( $\gamma$-linolenic acid), and C20:0 (arachidic acid), were obtained by weighing given amounts of fatty acid standards and dissolving in a $1: 1(\mathrm{v} / \mathrm{v})$ methanol/chloroform 
mixture, so as to obtain a final (known) concentration of ca. $0.2 \mathrm{~mol} / 1$ for each free fatty acid standard. Aliquots of $100 \mu \mathrm{l}$ of all stock solutions of fatty acid standards were taken and added to enough volume of $1: 1 \quad(\mathrm{v} / \mathrm{v})$ methanol/chloroform so as to obtain a total sample volume of $6.0 \mathrm{ml}$. A volume of $4.5 \mathrm{ml}$ solution of internal standards containing 0.00316 $\mathrm{mol} / \mathrm{l}$ of $\mathrm{C} 9: 0$ (nonanoic acid) and 0.00185 $\mathrm{mol} / 1$ of $\mathrm{C} 17: 0$ (margaric acid) in a $1: 1(\mathrm{v} / \mathrm{v})$ methanol/chloroform mixture prepared according to a similar procedure and further stabilized with $0.05 \%$ butylated hydroxyanisole was then added so as to obtain a final $4: 3$ ratio of sample volume to internal standard solution volume. This procedure was independently used for other aliquots of the fatty acid standard stock solutions, viz. 200, 300, 400, and $500 \mu \mathrm{l}$. Aliquots $(100 \mu \mathrm{l})$ of each resulting solution were withdrawn and added to $4.0 \mathrm{ml}$ of a $1 \mathrm{~g} / 1$ solution of $p$-bromophenacylbromide in acetonitrile. To the resulting solution, $80 \mu \mathrm{l}$ of a $5 \mathrm{~g} / 1$ solution of 18-crown-6-ether in acetonitrile was added, and this procedure was followed by addition of $0.2 \mathrm{~g}$ of potassium carbonate. After thorough mixing, this biphasic mixture was incubated at $75-80^{\circ} \mathrm{C}$ for $30 \mathrm{~min}$ (in order to promote derivatization), allowed to cool to near room temperature, added with $40 \mu \mathrm{l}$ of a $40 \mathrm{~g} / 1$ solution of formic acid in acetonitrile (so as to quench the derivatization reaction), and finally incubated at $75-80^{\circ} \mathrm{C}$ for an additional period of $5 \mathrm{~min}$. Following refrigeration for at least $1 \mathrm{~h}$ (at ca. $4^{\circ} \mathrm{C}$ ), samples were cold-filtered through $0.45 \mu \mathrm{m}$ nylon membrane filters.

For actual experiments, samples of 150 or $250 \mu 1$ (for the reactant mixtures or plain melted butterfat, respectively) were withdrawn from the reaction mixture at predetermined time intervals and put in vials containing $2.25 \mathrm{ml}$ of the internal standard solution and ca. $2 \mathrm{~g}$ of anhydrous sodium sulphatc. From this solution, a volume of $500 \mu 1$ was withdrawn and poured to another vial containing $4 \mathrm{ml}$ of $p$-bromophenacylbromide. After this point, the derivatization procedure was the same as for calibration.
In either situation, aliquots of $20 \mu$ l of the filtered samples were injected into the HPLC system; scparation was effected at $33^{\circ} \mathrm{C}$ using a mobile phase of water, methanol, and acetonitrile under a gradient system. The flow rate of eluant was $1 \mathrm{ml} / \mathrm{min}$, and absorbance of the eluate was read at $254 \mathrm{~nm}$.

\subsubsection{Thermal assays}

Thermal analyses of initial mixtures and lipase-modified mixtures of butterfat with oleic acid were accomplished via differential scanning calorimetry using high-pressure aluminum cells sealed under nitrogen. Fat samples weighing typically $10-30 \mathrm{mg}$ were frozen to $-40^{\circ} \mathrm{C}$ with liquid nitrogen and heated to $80^{\circ} \mathrm{C}$ at a linear rate of $8^{\circ} \mathrm{C} / \mathrm{min}$; during this process the amount of heat absorbed by the butterfat samples was measured.

\subsubsection{Water assays}

The moisture contents of the substrates (butterfat, oleic acid, and mixtures thereof) were determined via coulometry; melted mixtures were weighed in a warm syringe, injected promptly into the Karl-Fischer's reaction vessel, and titrated with in situ generated iodine until the equivalence point.

\section{Results and discussion}

The water content of the butterfat feedstock ranged from ca. $350 \mathrm{ppm}$ in the beginning to ca. $300 \mathrm{ppm}$ after $150 \mathrm{~h}$ of reaction. The dried nitrogen had an average relative humidity of ca. $4.0 \%$, which corresponds to an average value of 0.04 for the $a_{\mathrm{w}}$ of the butterfat feedstock. The protein content of the crude $\mathrm{M} 10^{\mathrm{TM}}$ lipase powder was ca. $9.74 \%(\mathrm{w} / \mathrm{w})$ (BSA equivalent). The results pertaining to the concentrations of free fatty acids in butterfat undergoing lipasecatalyzed interesterification are plotted in Fig. 2. The total concentrations of free fatty acids and the ratio of concentrations of free saturated fatty acids to free unsaturated fatty acids are depicted 

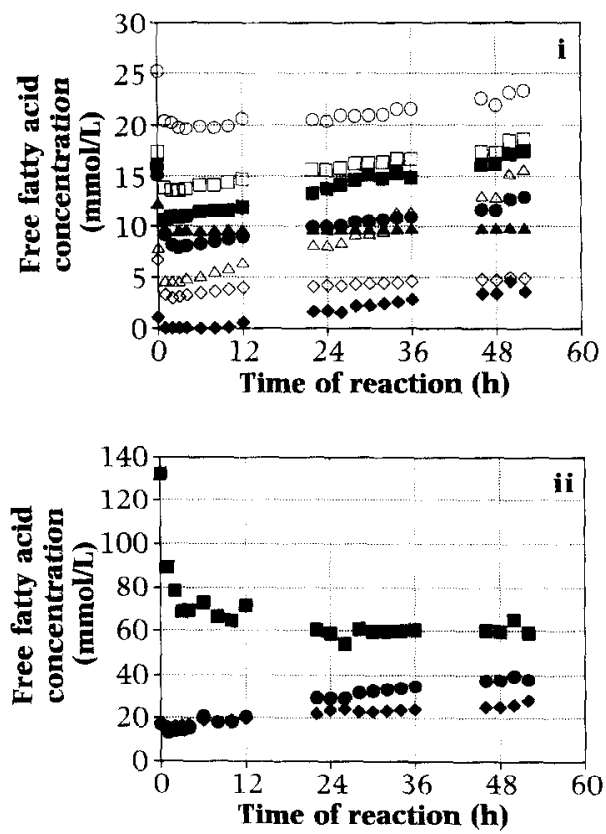

Fig. 2. Evolution of the concentrations of (i) free butyric (O), caproic $(\bigcirc)$, caprylic $(\square)$, capric $(\square)$, lauric $(\Delta), \gamma$-linolenic $(\Delta)$, myristic $(\diamond)$, and linoleic $(\diamond)$ acids, and (ii) free palmitic

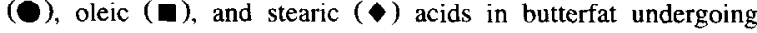
lipase-catalyzed reaction.

in Fig. 3. The thermograms of original butterfat and butterfat after lipase-catalyzed modification with oleic acid are depicted in Fig. 4.

The immobilization protocol was quite reproducible: e.g., in three consecutive experiments the amount of crude lipase immobilized was $6.36 \pm 0.89 \mu \mathrm{g}$ protein $/ \mathrm{cm}^{2}$ membrane, which

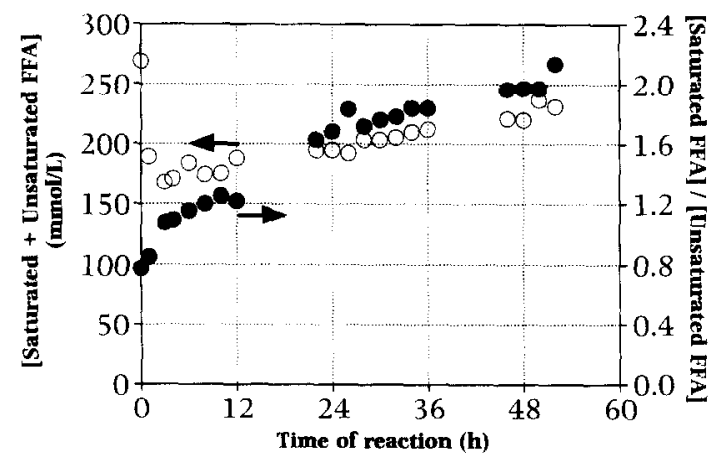

Fig. 3. Evolution of the total concentrations of free fatty acids and of the ratio of concentrations of saturated to unsaturated free fatty acids throughout reaction time.

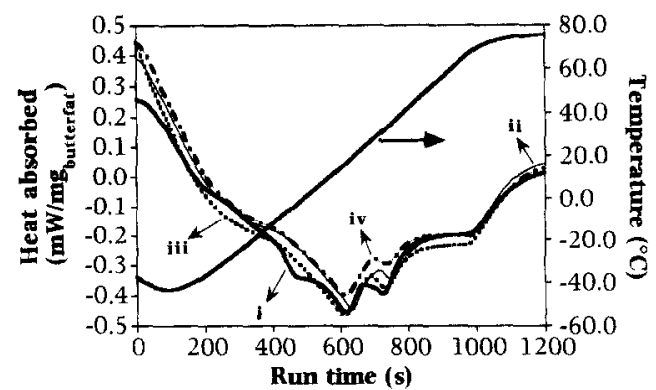

Fig. 4. Temperature ramp and associated thermograms of (i) original butterfat and lipase-modified butterfat after (ii) $10 \mathrm{~h}$, (iii) $30 \mathrm{~h}$, and (iv) $50 \mathrm{~h}$ of reaction.

corresponds to an immobilization yield of ca. $56.2 \%$ of the protein in the supernatant solution.

Performance of the lipase-catalyzed reaction using the hollow-fiber setup described above leads to a preferential net release of fatty acid residues of medium-chain length (especially myristic) and of long-chain length (especially palmitic), which is consistent with the reported substrate specificity of this microbial lipase [15] and the total fatty acid composition of typical bovine butterfat [6]. Inspection of Fig. 2 indicates high degrees of release of such (reportedly hypercholesterolemic) fatty acids as lauric acid, myristic acid, and stearic acid, viz. $71 \%, 100 \%$, $66 \%$, and $60 \%$ (calculated as final amount in modified butterfat minus initial amount in original butterfat normalized by the former). The concentration of free oleic acid was significantly reduced by $55 \%$ (calculated as initial amount in modified butterfat minus final amount in modified butterfat normalized by the former), which thus indicates a high degree of incorporation in the engineered butterfat.

As apparent from inspection of Fig. 3, a preferential release of saturated (S) fatty acids existed relative to unsaturated (U) counterparts over the whole timeframe of reaction, and this (almost) linear increase in the [S]/[U] ratio throughout time implies a pseudo-zero order gradual interesterification of butterfat glycerides with added oleic acid. This figure also shows that the total of free fatty acids in the reaction medium decreases during the first hours of reac- 
tion (thus indicating net esterification), followed by a slow increase after ca. $12 \mathrm{~h}$ (thus indicating net hydrolysis).

Taking the initial free fatty acid content of butterfat as negligible (as confirmed by our assays) and based on the average overall composition of butterfat in terms of fatty acid residues [6], the average molecular weight of fatty acids esterified in butterfat is ca. 218.55 $\mathrm{g} / \mathrm{mol}$; assuming that butterfat is composed of triglyceride molecules only and recalling that the density of butterfat at $40^{\circ} \mathrm{C}$ is ca. 0.905 $\mathrm{g} / \mathrm{ml}[16]$, then the theoretical amount of fatty acids released from butterfat in the case of complete hydrolysis would lead to a total concentration of ca. $4.0 \mathrm{~mol} / 1$. Combining this value with Fig. 2, one finally concludes that net hydrolysis of butterfat has occurred to an extent below $2 \%$; this figure is rather low when compared with the degree of acidolysis of ca. 76\% (obtained as $(\alpha-\beta) /(\delta-\varphi)$, where $\alpha$ is the amount of free oleic acid in the initial butterfat added with oleic acid, $\beta$ is the content of free oleic acid in the corresponding modified butterfat after $50 \mathrm{~h}$ of reaction, $\delta$ is the content of free oleic acid in modified butterfat (with no addition of free oleic acid) after $50 \mathrm{~h}$ of reaction, and $\varphi$ is the content of free oleic acid in regular butterfat). Inspection of Fig. 2 also indicates that about half of the total oleic acid added to butterfat was incorporated in the glycerides of butterfat after ca. $16 \mathrm{~h}$ of reaction.

The melting curves of the original butterfat added with oleic acid and of the modified butterfat after 10, 30, and $50 \mathrm{~h}$ of reaction (see Fig. 4) are similar in shape. Differences exist, however, in the melting point of the shorter chain fractions (melting point has changed from $31.31^{\circ} \mathrm{C}$ in the initial butterfat mixture to $32.68^{\circ} \mathrm{C}$ in the butterfat mixture interesterified for $10 \mathrm{~h}$ and to $30.80^{\circ} \mathrm{C}$ in the butterfat mixture interesterified for $50 \mathrm{~h}$ ), and in the melting point of the longer chain fractions (melting point has changed from $16.53^{\circ} \mathrm{C}$ in the initial butterfat mixture to $15.99^{\circ} \mathrm{C}$ in the butterfat mixture interesterified for $10 \mathrm{~h}$ and to $13.84^{\circ} \mathrm{C}$ in the butterfat mixture interesterified for $50 \mathrm{~h}$ ). The spread of the melting range thus changes from $14.78^{\circ} \mathrm{C}$ in the initial butterfat added with oleic acid to $16.69^{\circ} \mathrm{C}$ and to $17.02^{\circ} \mathrm{C}$ after 10 and 30 $h$ of reaction, respectively, but from then on the spread of the melting range becomes nearly constant, thus indicating that longer processing times are immaterial if melting behavior modification is sought. These observations, which are in agreement with results obtained elsewhere [9], can probably be accounted for by the considerable decrease in the concentration of longchain unsaturated fatty acids in free form (see Fig. 2ii) coupled with the concomitant increase in the concentration of triglycerides containing long-chain unsaturated fatty acid residues, which decrease the melting point of the higher melting point fraction.

The results obtained in this research effort show that desired alterations in the glyceride composition of butterfat can be induced by use of a specific lipase, thus suggesting that lipasecatalyzed interesterification of butterfat is a technically feasible alternative to physical blending of fats or sodium methoxide-catalyzed interesterification of butterfat. Since oleic acid has been claimed to possess a positive effect towards reduction of cholesterol, a modified butterfat with higher nutraceutical properties could thus be obtained by exchange of (hypercholesterolemic) lauric, myristic, and palmitic acids in the glycerides of butterfat with externally supplied oleic acid. Since in physical blending there is a physically unstable incorporation of oleic acid, and because ingestion of this monounsaturated fatty acid in free form is not organoleptically appealing, its lipase-catalyzed esterified form should be able to overcome both drawbacks [17]. Furthermore, the fats obtained by physical blending are mainly mixtures of long-chain triglycerides and mediumchain triglycerides which are absorbed at either one of two peak values, whereas fats subject to lipase-catalyzed interesterification lead to a wider range of absorption rates which will then fit a wider variety of individuals [17]. Finally, 
use of an appropriate lipase permits selective exchange of fatty acid residues between the glyceride structure of butterfat and deliberately added free fatty acids, thus producing structured lipids, which contrasts with chemical reactions catalyzed by inorganic catalysts which are completely random in nature.

\section{Acknowledgements}

Partial funding for this research effort was provided through grants by FLAD (Portugal; Project "Lipase-catalyzed interesterification of butterfat with olive oil") and by Institut CANDIA (France; Project "Modification de la matiére grasse par des lipases immobilisées sur un réacteur à membrane'). Partial funding for author V.M.B. was provided through a Ph.D. fellowship by JNICT (Portugal; CIENCIA BD/2091/92-IF and PRAXIS XXI $\mathrm{BD} / 5317 / 95)$.

\section{References}

[1] T. Oba and B. Witholt, J. Dairy Sci. 77 (1994) 1790.

[2] T.A. Fuglia, K. Petruso and S.H. Feairheller, J. Am. Oil Chem. Soc. 70 (1993) 281.
[3] H. Kimoto, Y. Endo and K. Fujimoto, J. Am. Oil Chem. Soc. 71 (1994) 469.

[4] N.W. Christie, in: P.F. Fox (Ed.), Developments in Dairy Chemistry, Vol. 2 (Elsevier Applied Science, London, 1983) p. 1.

[5] M. Safari and S. Kermasha, J. Am. Oil Chem. Soc. 71 (1994) 969.

[6] W.W. Nawar, in: O.R. Fennema (Ed.), Food Chemistry (Marcel Dekker, New York, 1985) p. 139.

[7] P. Kalo, H. Huotari and M. Antila, Milchwissenschaft 45 (1990) 281.

[8] L.H. Posorske, G.K. LeFebvre, C.A. Miller, T.T. Hansen and B.L. Glenvig, J. Am. Oil Chem. Soc. 65 (1988) 922.

[9] P. Kalo, P. Parviainen, K. Vaara, S. Ali-Yrrkö and M. Antila. Milchwissenschaft 41 (1986) 82.

[10] R.M.C. Dawson, W.H. Elliott, D.C. Elliott and K.M. Jones, Data for biochemical research (Oxford Science Publications, Oxford, 1969) p. 427.

[11] J.F. Robyt and B.J. White, Biochemical Techniques - Theory and Practice (Waveland, IL, 1990).

[12] V.M. Balcão, M.C. Vieira and F.X. Malcata, Biotechnol. Prog. 12 (19\%) 164.

[13] H.S. Garcia, H.R. Reyes, F.X. Malcata, C.G. Hill and C.H. Amundson, Milchwissenschaft 45 (1990) 757.

[14] F.X. Malcata, Ph.D. thesis, University of Wisconsin, Madison, USA (1991) p. 196.

[15] T. Mase, in: Lipase List of Amano Pharmaceuticals (Nagoya, 1988).

[16] F.E. Kurtz, in: B.H. Webb and A.H. Johnson (Eds.), Fundamentals of Dairy Chemistry (AVI Publishing Company, Westport, CT) p. 161.

[17] A.P. Carvalho and F.X. Malcata, The World of Ingredients, March/April (1996) 22. 